\title{
Consequences of avascular necrosis of the femoral head in aluminium-related renal osteodystrophy and the role of endochondral ossification in the repair process
}

\author{
J MCCLURE, PS SMITH
}

From the Division of Tissue Pathology, Institute of Medical and Veterinary Science, Frome Road, Adelaide, South Australia 5000

SUMMARY A patient with chronic renal failure, a dialysis encephalopathy syndrome and renal osteodystrophy associated with aluminium intoxication developed an avascular necrosis of the left femoral head. Histological examination of the excised head confirmed the zone of avascular necrosis and demonstrated an exuberant formation of cartilage around this zone. Calcification was sparse and the cartilage exhibited histological features similar to those seen in classical rickets. Histochemical and electron probe $x$-ray microanalysis demonstrated aluminium in the matrix around hypertrophic chondrocytes, at the tide mark of articular cartilage and at the mineralised tissue/osteoid interface of trabecular bone. Aluminium, therefore, preferentially localises at sites of calcification and possibly exerts an inhibitory effect on this reaction. This is taken to account for the relative failure of endochrondral ossification and the development of a rachitic appearance. A comparison with five other examples of avascular necrosis of the femoral head (occurring after renal transplantation, as an idiopathic phenomenon and as a complication of steroid therapy) showed that, in addition to the more commonly described appositional bone formation, cartilage formation and endochondral ossification were present in three of these comparison cases, although less prominent and of considerably less degree than in the main case.

Aluminium intoxication from the haemodialysis fluid during regular intermittent haemodialysis has been implicated in the aetiopathogenesis of the dialysis encephalopathy syndrome and dialysis-related renal osteodystrophy. ${ }^{1}$ Aluminium has been localised at the mineralised tissue/osteoid interface-that is, the calcification front site-in patients with the dialysis encephalopathy syndrome and significant bone disease. ${ }^{2}$ We have had the opportunity of studying the excised femoral head of a patient who developed avascular necrosis of the head and who had chronic renal failure complicated by a dialysis encephalopathy syndrome and osteomalacic bone disease with proved intra-osseous aluminium. The material was studied by histological, histochemical and electron probe $x$-ray microanalytical techniques

Accepted for publication 7 October 1982 and a comparison was made with avascular necrosis of the femoral head in two cases occurring after renal 8 transplantation, two cases complicating steroid $₹$ therapy and one case of idiopathic avascular necrosis.

Patients and methods

CLINICAL FEATURES

The main case was 59-year-old man with chronic renal 0 failure due to left polycystic disease and congenital N్ absence of the right kidney. He had been on haemodialysis for 24 months and during that time had developed increasing left upper thigh pain. $\mathrm{He} \frac{\mathrm{C}}{\Phi}$ walked with an antalgic gait. The right hip showed a? full range of movement. On the left side flexion was 7 $110^{\circ}$, abduction $30^{\circ}$, abduction $20^{\circ}$ and rotational $\bar{O}$ movements were full. An $x$-ray examination of the left hip showed segmental collapse of the femoral head (Fig. 1). A left Charnley total hip replacement (THR) was performed. 
This patient also had evidence of a dialysis encephalopathy syndrome with "shakes" after haemodialysis accompanied by slurring of speech, short-term memory loss and a marked intention tremor.

The clinical features of the five comparison cases (Nos 2 to 6) are summarised in Table 1. Considering all cases the mean age was $52 \mathrm{yr}$ (range 29 to $72 \mathrm{yr}$ ) and there were four men and two women. Three cases had chronic renal failure and two of these had had renal transplants. Four of the comparison cases were being or had been treated with corticosteroids. The mean time interval from the onset of symptoms to THR was 13 months (range three to 24 months).

\section{MATERIAL AND METHODS}

The excised femoral heads were cut serially into $4 \mathrm{~mm}$ to $5 \mathrm{~mm}$ thick slices in the coronal plane using a bandsaw. The slices were fixed in $10 \%$ buffered formalin for a minimum period of $48 \mathrm{~h}$. Selected whole slices were embedded in Araldite without prior decalcification. Thin $(7 \mu \mathrm{m})$ sections were cut with a Jung $\mathrm{K}$ microtome. Multiple sections were stained by the von Kossa technique with various counterstains including haematoxylin and eosin (HE) and the van Gieson method. Sections were also stained by the aluminon method for the demonstration of aluminium salts. ${ }^{3}$

Bone biopsies from the left anterior iliac crest were available in three cases. These had been taken at different times in relation to the excision of the femoral head. In addition to the staining methods

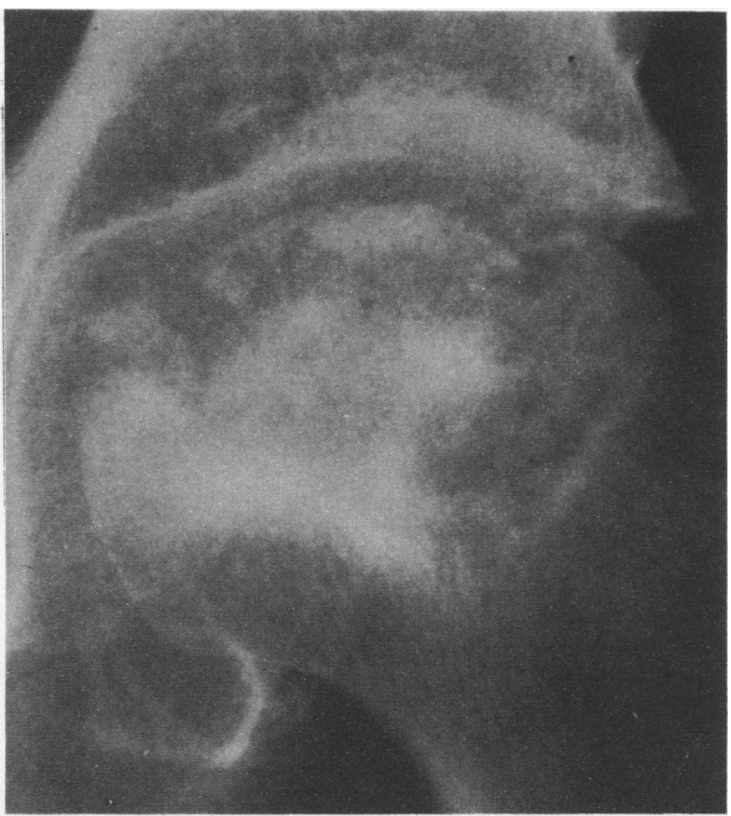

Fig. 1 Left hip joint ( $x$-ray) of case 1 showing segmental collapse of femoral head.

described above, calcification fronts were stained with toluidine blue and with haematoxylin. ${ }^{4}$ The total cancellous bone volume (TBV), the osteoid volume $(\mathrm{OV})$ and the percentage of the total bone volume which was mineralised $(\% \mathrm{M})$ were estimated from

Table 1 Summary of clinical findings in patients 2 to 6

\begin{tabular}{|c|c|c|c|c|c|c|c|}
\hline Case & Age (yr) & Sex & Antecedent disease & Drugs & Symptoms and signs & $x$-ray & Treatment \\
\hline 2 & 50 & $\mathbf{M}$ & $\begin{array}{l}\text { Chronic renal } \\
\text { failure (CRF) due } \\
\text { to polycystic } \\
\text { disease. }\end{array}$ & $\begin{array}{l}\text { Prednisolone } \\
\text { Azathioprine. }\end{array}$ & $\begin{array}{l}\text { Pain in left hip with limita- } \\
\text { tion of external rotation } \\
\text { developed } 10 \text { months after } \\
\text { renal transplant. }\end{array}$ & $\begin{array}{l}\text { Subchondral bone } \\
\text { in a crescent shape in } \\
\text { both femoral heads } \\
\text { suggestive of avascular } \\
\text { necrosis } L>R \text {. }\end{array}$ & $\begin{array}{l}\text { Left Charnley total hip } \\
\text { replacement (THR) } \\
18 \text { months after onset } \\
\text { of pain. }\end{array}$ \\
\hline 3 & 29 & $\mathbf{M}$ & $\begin{array}{l}\text { CRF due to renal } \\
\text { artery disease and } \\
\text { hypertension. }\end{array}$ & $\begin{array}{l}\text { Prednisolone } \\
\text { Azathioprine. }\end{array}$ & $\begin{array}{l}\text { Pain in both knees, severe on } \\
\text { left side. No physical } \\
\text { abnormality of knees. } \\
\text { Limitation of abduction and } \\
\text { internal rotation, left hip } \\
\text { developed } 5 \text { months after } \\
\text { renal transplant. }\end{array}$ & $\begin{array}{l}\text { Sclerosis and } \\
\text { deformity of the heads } \\
\text { of both femora with } \\
\text { lucent areas consistent } \\
\text { with avascular } \\
\text { necrosis } L>R \text {. }\end{array}$ & $\begin{array}{l}\text { Left Charnley THR } \\
3 \text { months after the } \\
\text { onset of pain. }\end{array}$ \\
\hline 4 & 72 & $F$ & $\begin{array}{l}\text { Rheumatoid } \\
\text { arthritis but never } \\
\text { treated with } \\
\text { steroids. }\end{array}$ & & $\begin{array}{l}\text { Pain in lett groin, thigh and } \\
\text { knee for one year. }\end{array}$ & $\begin{array}{l}\text { Segmental collapse } \\
\text { of left femoral head. }\end{array}$ & $\begin{array}{l}\text { Left Charnley THR } \\
15 \text { months after onset } \\
\text { of pain. }\end{array}$ \\
\hline 5 & 35 & $F$ & $\begin{array}{l}\text { Systemic lupus } \\
\text { erythematosus } \\
\text { diagnosed } 15 \\
\text { years previously. }\end{array}$ & $\begin{array}{l}\text { Cortico- } \\
\text { steroids for } \\
8 \text { years after } \\
\text { diagnosis of } \\
\text { SLE. }\end{array}$ & $\begin{array}{l}\text { Painful right hip diagnosed } \\
7 \text { years after cessation of } \\
\text { corticosteroid treatment. }\end{array}$ & $\begin{array}{l}\text { Deformity and } \\
\text { sclerosis of right } \\
\text { femoral head. }\end{array}$ & $\begin{array}{l}\text { Right Muller THR } \\
6 \text { months after onset } \\
\text { of pain. }\end{array}$ \\
\hline 6 & 68 & $\mathbf{M}$ & $\begin{array}{l}\text { Vague hyper- } \\
\text { allergic state. }\end{array}$ & $\begin{array}{l}\text { Cortico- } \\
\text { steroids for } \\
\text { several years. }\end{array}$ & $\begin{array}{l}\text { Developed a painful right } \\
\text { hip with limitation of } \\
\text { movement. }\end{array}$ & $\begin{array}{l}\text { Deformity, segmental } \\
\text { collapse of right } \\
\text { femoral head. }\end{array}$ & $\begin{array}{l}\text { Right Charnley THR } \\
12 \text { months after onset } \\
\text { of pain. }\end{array}$ \\
\hline
\end{tabular}


multiple sections (treated by the von Kossa technique and the van Gieson counterstain) using the Quantimet Image Analysis computer. The percentage of the trabecular surface covered by osteoid (OS), the extent of the calcification fronts (CFE) as a percentage of osteoid seams and the total resorbing surfaces (RS) were estimated by line-intersect techniques using an eyepiece graticule. An assessment of the thickness of the osteoid seams was made by counting the maximum number of birefringent lamellae (MOL) seen in polarised light.

An Araldite-embedded slice from case 1 was divided into seven portions each measuring $20 \times 5$ $\mathrm{mm}$. The surface of each portion was polished to within $1 \mu \mathrm{m}$ using diamond paste, coated with carbon and analysed with a Jeol 733 Superprobe scanning electron microanalyser using the wavelength dispersive $x$-ray analytical mode of the instrument. Areas were examined at a standard magnification and the secondary electron images photographed, after which the distribution of aluminium, calcium and phosphorus were assessed. Linear focusing Bragg crystal spectrometers with LIF, TAP and PET crystals were used for $x$-ray detection using calcium phospate and aluminium oxide as standards. The instrument was equipped with two spectrometer channels which allowed the simultaneous detection of calcium and aluminium. Elemental distribution was also assessed by a linear scan over a known area of specimen. This was accomplished by sequential specimen movement with $2 \mu \mathrm{m}$ steps and a twosecond rest period at each point during which $x$-ray count rates were recorded. The electron beam was held stationary throughout. The output from each spectrometer channel was transcribed by a pen-chart recorder.

\section{PATHOLOGICAL FEATURES}

The head of the femur from case 1 showed a wedgeshaped area of abnormality (Fig. 2). The articular cartilage overlying this area was wrinkled and partially detached, but contained viable chondrocytes with normal morphology and distribution. The internal part of this zone was composed of a small amount of well-mineralised trabecular bone whose lacunae were empty and in which the marrow spaces contained basophilic amorphous debris (zone of $\overrightarrow{0}$ necrotic bone). Surrounding this was a thick band of $\overrightarrow{\vec{H}}$ hyaline cartilage. The constituent chondrocytes were $\omega$ small and of uniform size. Only in an occasional focus was there cell hypertrophy with matrical calcification (cartilaginous zone).

Around the outside periphery of this zone of $w$ hyaline cartilage and merging imperceptibly with it, of there was an osteoidal zone with an eosinophilic o matrix containing a large number of collagen fibres which were readily seen in polarised light (Fig. 3). $\bar{z}$ This material was associated with small fusiform cells and appeared to be condensing out of mesenchymal $\stackrel{\rho}{\zeta}$ tissue. More peripherally there were thick osteoid $\vec{\bullet}$ trabeculae communicating with this material and $\underset{c}{\oplus}$ thick poorly mineralised trabeculae which surrounded and delineated the total area. In the intervening zone the intertrabecular spaces contained vascular fibrous tissue with dilated blood vessels. The surfaces of non-mineralised osteoid trabeculae were covered by numerous multinucleated cells identical to osteoclasts. Many of these cells occupied indentations of the trabecular surfaces. Similar cells occupied indentations of the surface of that part of the chondroid matrix showing eosinophilia.

Positive histochemical reactions for the presence of aluminium were observed in the bone trabeculae of

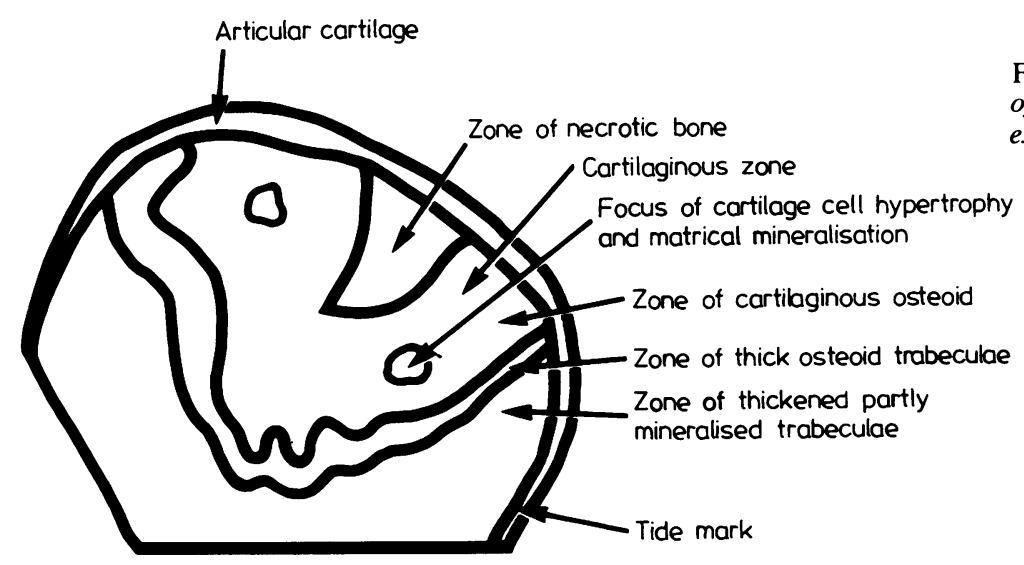

Fig. 2 Diagrammatic representation of the zones of abnormality in the excised femoral head of case 1. 
the femoral head outside the abnormal zone. These trabeculae were extensively covered by thick osteoid seams (up to 10 birefringent lamellae) and extensive positive reactions (red/purple lines) were present at the osteoid/mineralised tissue interface-that is, at the calcification front site-Fig. 4. Fainter lines of positive reaction were present in the mineralised trabecular matrix in a disposition corresponding to the cement lines. Positive histochemical reactions were not present in the osteoid. Positive reactions were, however, seen in two further locations. The first was along the "tidemark" at the junction of the hyaline articular cartilage and the underlying mineralised tissue (Fig. 5). The second was at the few foci of cartilage cell hypertrophy and related matrical calcification in the abnormal zone (Figs. 6 and 7). The tidemark reaction was linear and somewhat irregular and diffuse in disposition. The reaction in the cartilage precisely matched the extent of the von Kossa reaction, but was most prominent immediately around the chondrocyte lacunae.

The secondary electron images obtained with the

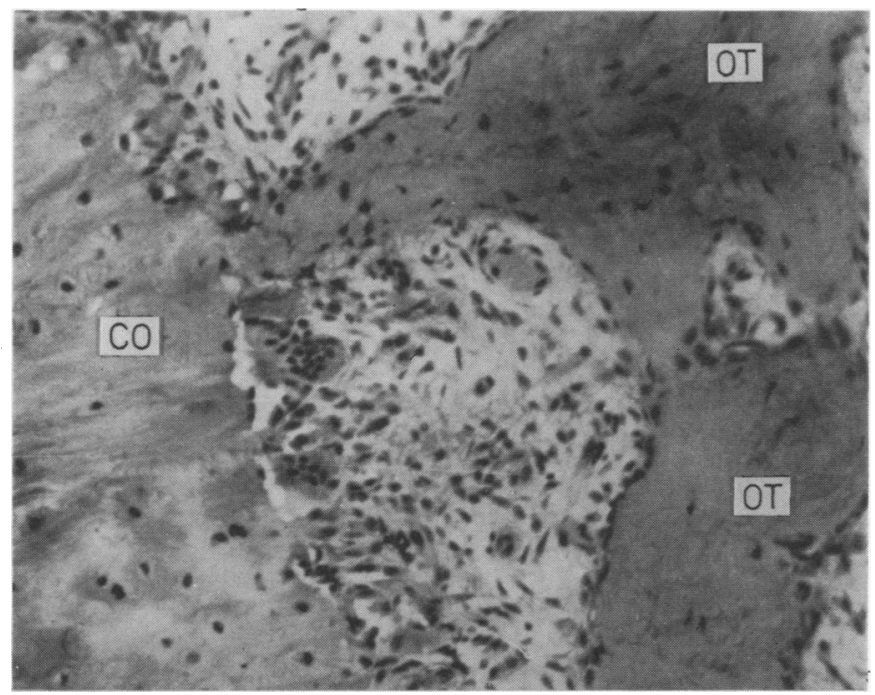

Fig. 3 Periphery of the zone of cartilaginous. osteoid (CO) which adjoins osteoid trabeculae (OT) (devoid of mineralisation), which are apparently being remodelled by multinucleated giant cells. Undecalcified, von Kossa and haematoxylin and eosin $\times 100$.

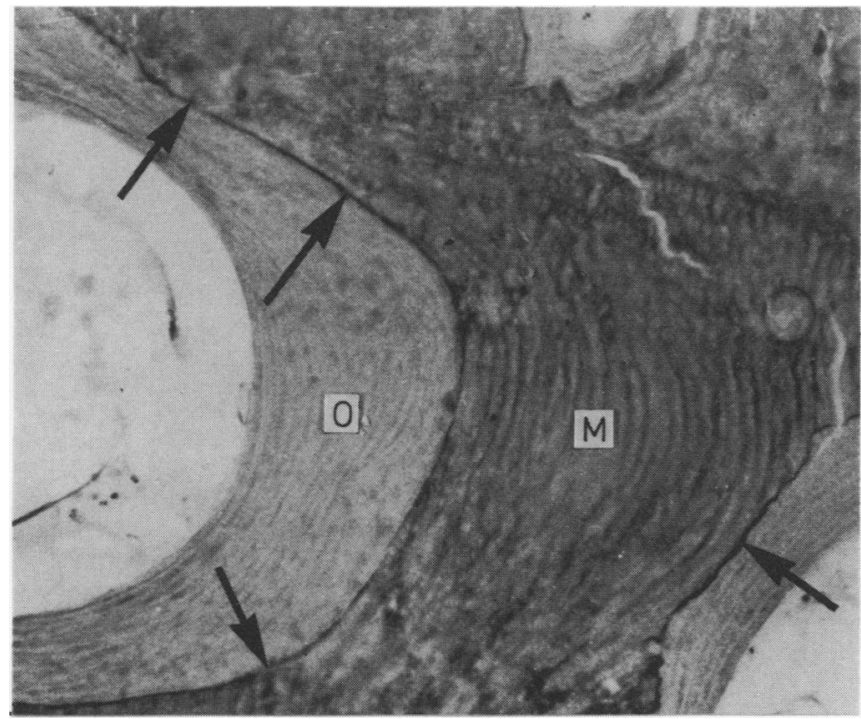

Fig. 4 The mineralised zones $(M)$ of the trabeculae are covered by thick osteoid seams $(O)$. The dark lines (arrowed) at the junction between zones and seams are the positive aluminon staining reactions for aluminium. Undecalcified, aluminon $\times 100$. 


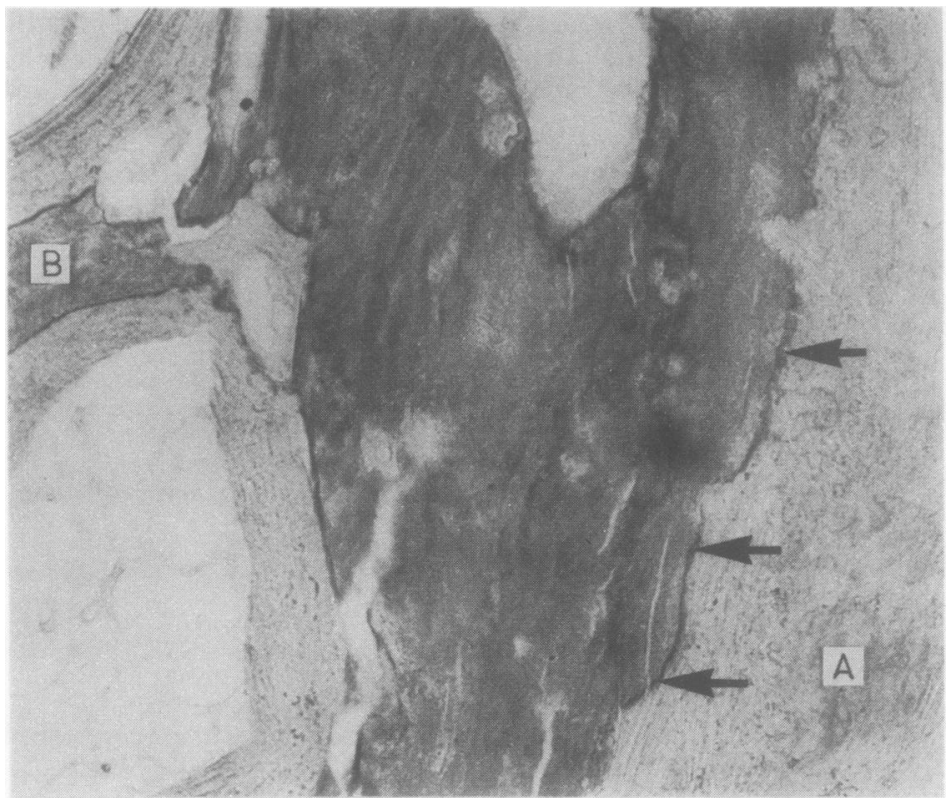

Fig. 5 The tidemark (arrowed) stains positively with aluminon. $A$ is articular cartilage and $B$ is subchondral bone. Undecalcified, aluminon $\times 100$.

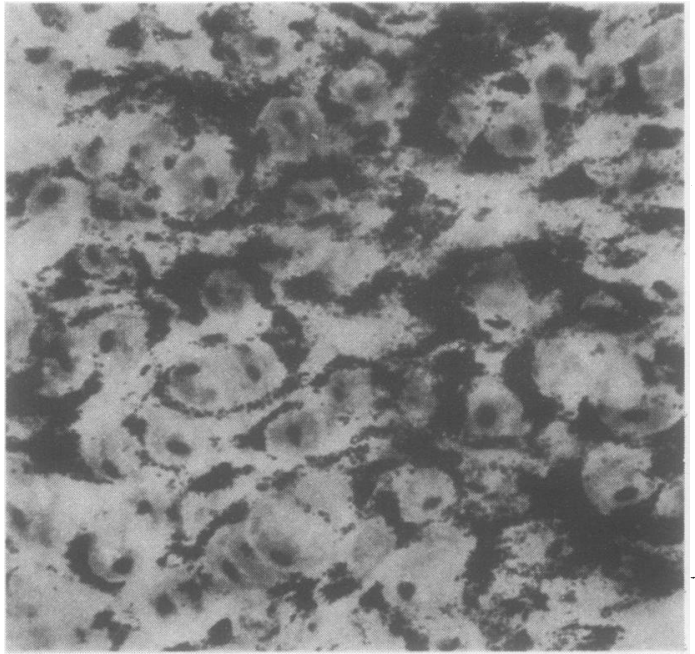

Fig. 6 Calcific deposits (black) around hypertrophic chondrocytes. Undecalcified, von Kossa and haematoxylin and $\operatorname{eosin} \times 200$.

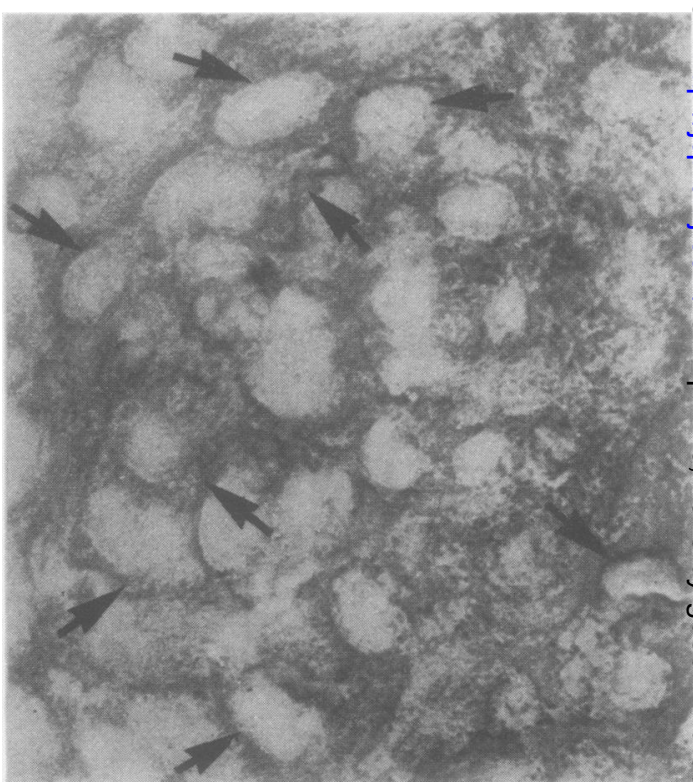

Fig. 7 Positive aluminon reactions (arrowed) around chondrocyte lacunae (empty circular spaces) in the same area as in Fig. 6. Undecalcified, aluminon $\times 200$. 
Jeol 733 Superprobe scanning electron microanalyser were of sufficient quality to allow precise identification of the various components of the zone of abnormality. Aluminium was not detected by area scan in the trabecular structures of the zone of necrotic bone. Aluminium was detected by area scan at the osteoid/mineralised tissue interface of trabecular bone, at the tidemark and in the calcified matrix around the few foci of hypertrophic chondrocytes. In the trabecular bone a combined linear elemental distributional profile for calcium and aluminium was constructed for a distance in excess of $600 \mu \mathrm{m}$ and passing from the mineralised zone of one trabecula across the mineralised tissue/osteoid interface, across the osteoid seam, through marrow and on to a second trabecula passing through identical structures in reverse order. Peaks of aluminium $x$-ray emission were precisely localised to the mineralised tissue/osteoid interface. Peaks were also observed in the marrow spaces probably in relation to blood vessels (Fig. 8).

Macroscopically in all the other cases there was a subchondral zone of pallor with some surrounding congestion. This area was roughly wedge-shaped and the base was in the immediate subchondral zone. In two instances (cases 2 and 3) a split ran through the zone of pallor lying roughly parallel to the articular surface. In case 2 a $10 \mathrm{~mm}$ diameter cyst was present.
Microscopically all the comparison cases had viable articular cartilage. In case 4 there was some focal thinning and fibrillation (signs of osteoarthrosis). Subchondral areas of necrosis were indicated by well mineralised trabeculae with empty osteocyte lacunae and surrounded by basophilic amorphous medullary debris. At the junction of viable and non-viable bone there was marrow fat necrosis and granulation tissue formation with osteoblastic trabecular appositional growth and remodelling of viable and non-viable trabecular structures by osteoclasts.

In cases 4, 5 and 6 near the junction of viable and non-viable bone there were also small foci of hyaline cartilage. These were discrete and apparently forming in situ from transformed mesenchymal cells. These nodules were in the same site as the cartilage zone in the main case, but in contrast did not form a wide cohesive band. The nodules were intimately related to mineralised bone trabeculae by a process of endochondral ossification identical to that seen in the epiphyseal growth plate (Figs. 9 and 10). Thus there was an observable sequence of chondrocyte proliferation, hypertrophy and matrical calcification with excavation of the calcified cartilage by multinucleated giant cell (chondroclasts) and the deposition of osteroid on the walls of the excavations by osteoblasts (cutting cone/forming cone process). This process of endochondral ossification was noted

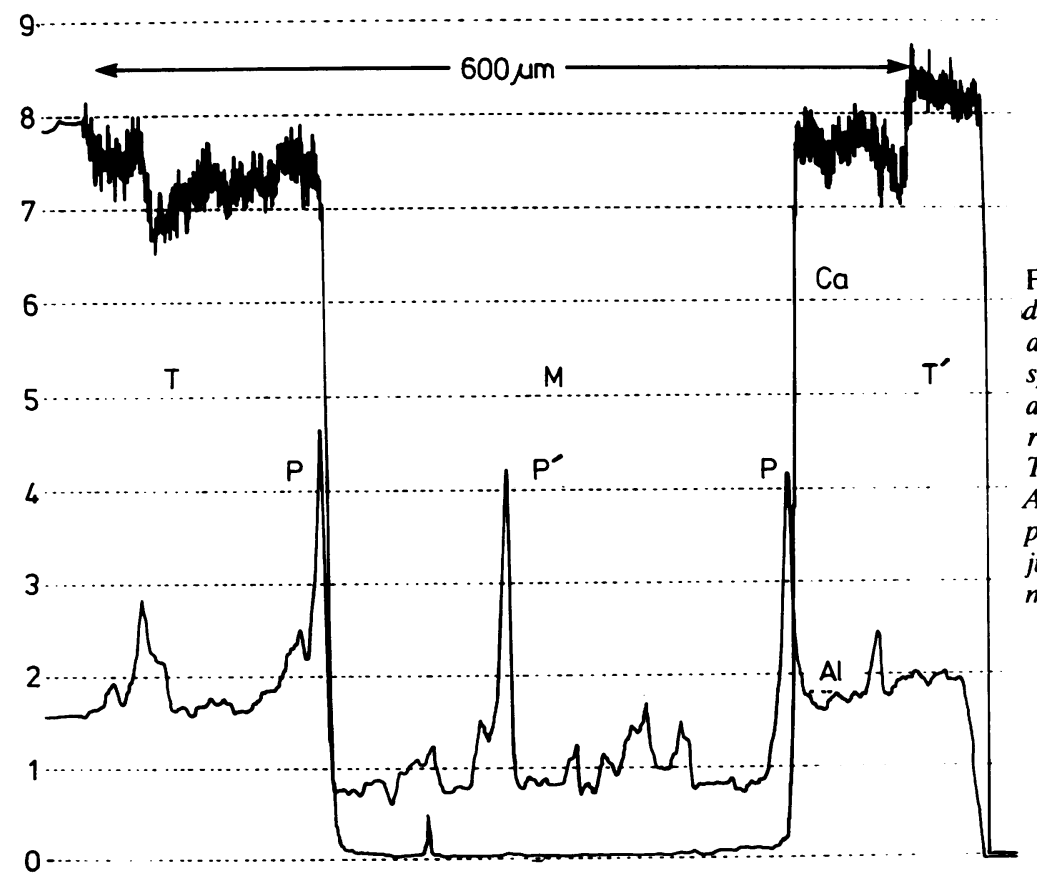

Fig. 8 Combined linear elemental distributional profile for calcium $(\mathrm{Ca})$ and aluminium (Al) across marrow space $(M)$ from one trabecula $(T)$ to another $\left(T^{\prime}\right)$. The Ca signal has been reduced in comparison to the Al signal. The Ca trace is slightly in advance of the Al trace so that Al peaks $(P)$ are precisely at the mineralised tissue/osteoid junction. The Al peak $\left(P^{\prime}\right)$ in the marrow is in relation to blood vessels. 


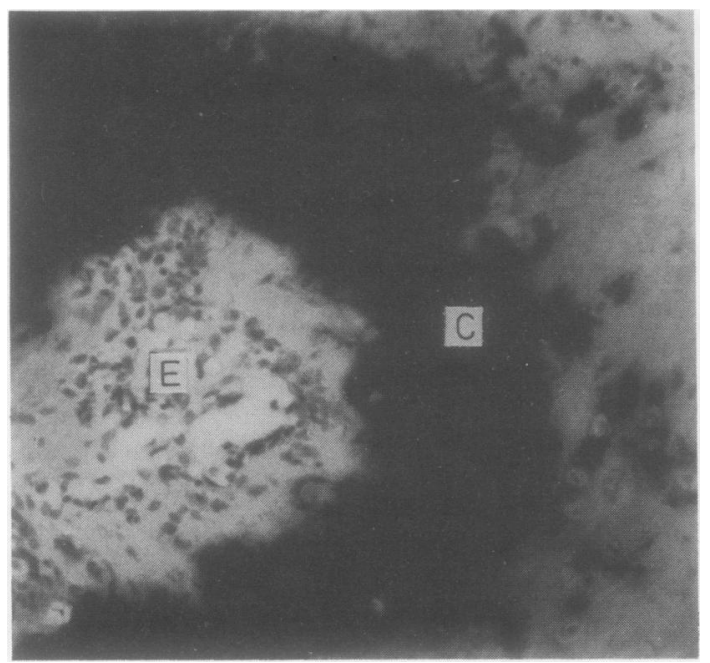

Fig. 9 Excavation (E) of a nodule of calcified cartilage matrix $(C)$ in case 4 is illustrated. This is part of a process of endochondral ossification. Undecalcified, von Kossa and haematoxylin and eosin $\times 100$.

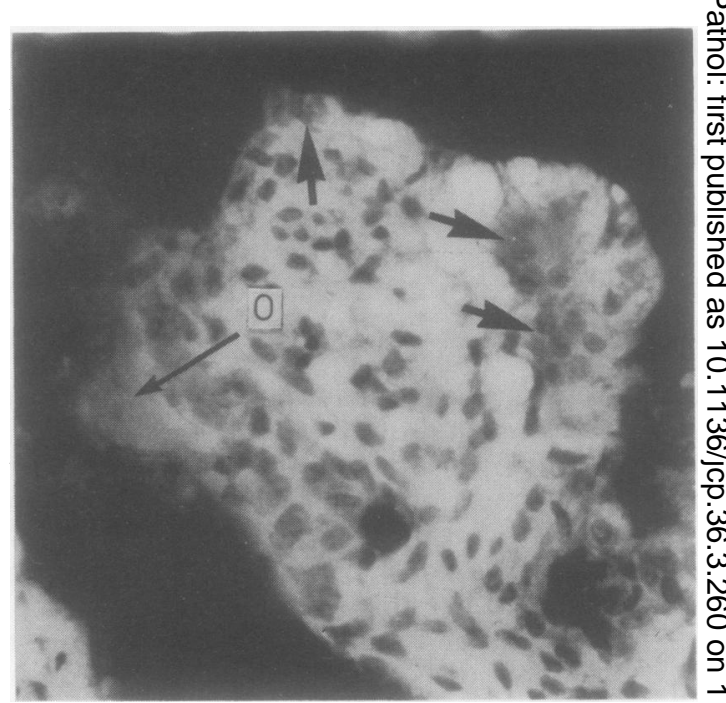

Fig. 10 Excavation of calcified cartilage matrix is by chondroclasts (arrowed). Some osteoid $(O)$ is being laid down on the walls of the excavation. Undecalcified, von Koss $a$ and haematoxylin and eosin $\times 200$.

Table 2 Histoquantitative data of iliac crest bone biopsies from cases 1, 2 and 3

\begin{tabular}{|c|c|c|c|c|c|}
\hline \multirow[t]{2}{*}{ Parameter } & \multirow[t]{2}{*}{ Normal values } & \multicolumn{2}{|c|}{ Case I } & \multirow[t]{2}{*}{ Case 2} & \multirow[t]{2}{*}{ Case 3} \\
\hline & & $A$ & $\boldsymbol{B}$ & & \\
\hline Total cancellous bone volume (TBV $=\%$ cancellous space) & $\begin{array}{l}<50 \text { yr of age } 15-29 \% \\
\geqslant 50 \mathrm{yr} \text { of age } 9-20 \%\end{array}$ & $16 \cdot 1$ & $19 \cdot 3$ & $17 \cdot 9$ & $13 \cdot 2$ \\
\hline$\%$ Mineralisation ( $\mathrm{M}=\%$ cancellous bone tissue $)$ & $>97.0 \%$ & $72 \cdot 8$ & $67 \cdot 7$ & $89 \cdot 6$ & $93 \cdot 1$ \\
\hline Osteoid volume (OV $=\%$ cancellous space) & $<0.3 \%$ & $4 \cdot 4$ & $6 \cdot 2$ & $1 \cdot 9$ & 0.9 \\
\hline Percentage of trabecular surface covered by osteoid (OS) & $\begin{array}{l}<50 \text { yr of age }<28 \% \\
>50 \mathrm{yr} \text { of age }<46 \%\end{array}$ & $91 \cdot 6$ & $92 \cdot 6$ & $83 \cdot 0$ & $75 \cdot 8$ \\
\hline Calcification front extents (CFE $=\%$ osteoid surface) & $>70 \%$ & $43 \cdot 8$ & $47 \cdot 5$ & $49 \cdot 0$ & $59 \cdot 4$ \\
\hline Maximum number of birefringent osteoid lamellae (MOL) & $<4$ & 5 & 6 & 5 & 4 \\
\hline Total resorbing surface ( $R S=\%$ total trabecular surface) & $<20.0 \%$ & $7 \cdot 2$ & $7 \cdot 2$ & $14 \cdot 0$ & $24 \cdot 2$ \\
\hline
\end{tabular}

The normal values are derived from iliac crest biopsies of 37 healthy subjects resident in the Adelaide area (13 males, 24 females) with no previous significant medical histories, no evidence of metabolic bone disease and whose biochemical parameters, including those of calcium $O$ metabolism and renal function, were within normal limits.

in addition to the appositional process described above. The latter occurred at the junction between viable and non-viable tissue, whilst the former tended to be "external" to this junction on the side of the viable zone.

Aluminium stains were performed on specimens from cases 2 and 6 and all were negative.

Iliac crest bone biopsy data from cases 1, 2 and 3 are given in Table 2 . Two biopsies were available from case 1 . The first (A) had been taken one year prior to total hip replacement. The second (B) had been taken at the time of operation. In case 2 the biopsy had been taken one year prior to operation and in case 3 three years before THR. In all iliac crest specimens there was clear evidence of osteomalacia with increased osteoid volumes and diminisheof calcification front extents. Additionally, in case $3_{\mathrm{N}}$ there was evidence of hyperparathyroidism in the increased total resorbing surface. In the excised ${ }^{\omega}$ femoral heads of these cases there was clear evidence? of osteomalacia in case 1 , but in the other tw\& (excised at appreciable time intervals after the ilia\& crest biopsies) there was no qualitative excess of osteoid and calcification fronts were readily visualise $\$$ in areas well away from the sites of avascular necrosis Positive aluminon reactions were observed in case $1 \frac{\mathrm{C}}{\mathrm{C}}$ biopsy $B$ being more extensively positive than $A$ ? Cases 2 and 3 biopsies exhibited negative reactions. 


\section{Discussion}

Avascular necrosis is associated with interruption of the blood supply to bone and is seen in fractured neck of femur, slipped femoral capital epiphysis or traumatic dislocation. It may also be seen in several diseases associated with arterial obstruction such as by Gaucher's cells in Gaucher's disease, in sickle cell anaemia, by nitrogen bubbles, atheromatous emboli, fibrosis following irradiation, neoplastic infiltration or inflammation associated with osteomyelitis. The lesion may also be seen as an idiopathic phenomenon. An association between avascular necrosis and corticosteroid therapy is well recognised. ${ }^{5}$ Avascular necrosis of the femoral head is a complication of renal transplantation and, whilst it is accepted that the necrosis in this situation is related to corticosteroid therapy, the pathogenetic mechanisms are controversial. ${ }^{67}$

The present study resulted from the examination of an unusual case of avascular necrosis of the femoral head in a patient with chronic renal failure on haemodialysis and without transplantation and corticosteroid therapy. Because of the results obtained a comparison was made with other examples of avascular femoral head necrosis of more conventional aetiology.

In the main case there was clinical evidence of a dialysis encephalopathy syndrome and histological evidence of osteomalacia. Aluminium was clearly demonstrated at the osteoid-mineralised tissue interface in cancellous bone. This is the site of the calcification front and the accumulation of aluminium at this site could clearly interfere with the mineralisation process and produce an appearance of osteomalacia. Aluminium accumulation at the calcification front has been observed in patients with chronic renal failure on intermittent haemodialysis, ${ }^{289}$ but its localisation in the matrix of hypertrophic cartilage and at the tidemark of calcified articular cartilage has not been previously reported.

The observations in the main case suggest that the accumulation of aluminium inhibited calcification of the cartilage matrix and, since in the classical process of endochondral ossification such calcification is followed by chondroclastic erosion and osteogenesis, bone formation was, therefore, also inhibited. Persistent differentiation and proliferation of cartilage lead to the formation of a large quantity of cartilage, thus producing in an adult a remarkable combination of rachitic cartilage and osteomalacic bone.

Peripherally the cartilage became quite eosinophilic and of an osteoidal appearance. This phenomenon has been called cartilaginous osteoid by Jaffé ${ }^{10}$ who described it as a feature of rachitic cartilage. However, this non-mineralised cartilaginous osteoid was remodelled into trabecular structures by multinucleated cells indistinguishable from osteoclasts. These trabecular structures contained cells indistinguishable from osteocytes and blended with conventional mineralised trabeculae. This process of bone formation from hyaline cartilage is different from the classical pathway (which involves calcification and erosion of the cartilage matrix) and suggests that there may be an alternative pathway for endochondral ossification which involves the transformation of chondrocytes into bone cells. Such an alternative pathway has important implications for the metabolic capabilities of the chondrocyte.

Although the large amount of cartilage formed in the main case demonstrates that it is possible for cartilage to be abundant, the formation of this material in the repair of avascular necrosis has been the subject of little comment. In her classical studies of avascular necrosis of the femoral head after transcervical fracture, Catto ${ }^{112}$ does not describe endochondral ossification in the repair process. Glimcher and Kenzora ${ }^{13}$ illustrate cartilage differentiation in the zone between necrotic bone and repaired viable bone in avascular necrosis after transcervical fracture and suggest that this occurs as a response to motion and shearing stresses at the site of a secondary intracapital fracture. Patterson $e t a^{14}$ describe the formation of fibrocartilage with conversion to bone by endochondral ossification in their cases of idiopathic avascular necrosis of the femoral head.

Therefore, a close scrutiny was made of five other examples of femoral head avascular necrosis to determine the presence or absence of cartilage proliferation and endochondral ossification in the repair process. In the two cases occurring after renal transplantation, cartilage proliferation was not observed. Appositional new bone formation was observed, a feature of the repair process which is commonly emphasised..$^{1213}$ In these two cases there were splits in the subchondral bone with no vital reactions. It may be that when the ingrowing vascular granulation tissue reaches these splits then movement and shearing stresses result in chondroid differentiation followed by endochondral ossification. Because of close clinical monitoring before and after transplantation in these two cases, the duration of symptoms probably matched the duration of the avascular necrosis and excision of the femoral heads occurred relatively early.

In the other three comparison cases focal chondroid differentiation with associated endochondral ossification was observed. In these cases avascular necrosis may well have antedated removal of the femoral heads by a considerable period and chondroid differentiation with endochondral ossification may be 
a late feature of the repair process. Also the cartilage formed may be relatively inconspicuous since transformation to bone may in the usual situation be quite rapid. Therefore, in addition to appositional new bone formation, endochondral ossification does play a role in the repair of avascular necrosis and the main case drew attention to this by virtue of the mineralisation of cartilage being blocked by aluminium intoxication.

We wish to thank Mr W Mussard of the Lapidary Laboratory of the Department of Economic Geology, University of Adelaide, for help with the preparation of blocks for electron probe analysis. We wish to acknowledge the assistance of Mr B Griffin in the performance of the electron probe anaylsis at the Electron Optical Centre, University of Adelaide.

\section{References}

' Parkinson IS, Ward MK, Kerr DNS. Dialysis encephalopathy, bone disease and anaemia: the aluminium intoxication syndrome during regular haemodialysis. $J$ Clin Pathol 1981;34:1285-94.

${ }^{2}$ Smith PS, McClure J. Localisation of aluminium by histochemical and electron probe $x$-ray microanalytical techniques in bone tissue of cases of renal osteodystrophy. J Clin Pathol 1982;35: 1283-93.

${ }^{3}$ Irwin DA. The demonstration of aluminium in animal tissues. Arch Indust Health 1955;12:218-20.

${ }^{4}$ Raina V. Normal osteoid tissue. J Clin Pathol 1972;25:229-32.
${ }^{5}$ Fisher DE, Bickel WH. Corticosteroid-induced avascular necrosis. A clinical study of seventy-seven patients. J Bone $J t$. Surg 1971;53-A:859-73.

${ }^{6}$ Starzl TE, Marchioro TL, Porter KA, Moore CA, Rifkind D, Waddell WR. Renal homotransplantation. Late function and complications. Ann Intern Med 1964;61:470-97.

${ }^{7}$ Ibels LS, Alfrey AC, Huffer WE, Weil R. Aseptic necrosis of bone $\overline{\bar{c}}$. following renal transplantation. Experience in 194 transplant $\vec{\nabla}$ recipients and review of the literature. Medicine 1978;57:25-45. §

${ }^{8}$ Cournot-Witmer G, Zinegraff J, Plachot JJ et al. Aluminium localisation in bone from haemodialysed patients: relationship to matrix mineralisation. Kidney Int 1981;20:375-85.

${ }^{9}$ Buchanan MRC, Ihle BU, Dunn CM. Haemodialysis-related osteomalacia: a staining method to demonstrate aluminium. $J \bar{\omega}$ Clin Pathol 1981;34:1352-4.

${ }^{10} \mathrm{Jaffé}$ HL. Metabolic, degenerative and inflammatory diseases of $\frac{7}{0}$ bones and joints. Philadelphia: Lea and Febiger, 1972.

"Catto M. A histological study of avascular necrosis of the femoral head after transcervical fracture. J Bone Jt Surg 1965;45-B:749- $\omega$ 76.

${ }^{12}$ Catto $M$. The histological appearances of late segmental collapse of the femoral head after transcervical fracture. J Bone Jt Surg 1965;47-B:777-91.

${ }^{13}$ Glimcher MJ, Kenzora JE. The biology of osteonecrosis of the human femoral head and its clinical implications: II The $\bar{z}$ pathological changes in the femoral head as an organ and in the hip joint. Clin Orthop 1979;139:283-312.

${ }_{14}$ Patterson RJ, Bickel WH, Dahlin DC. Idiopathic avascular necrosis of head of the femur. J Bone Jt Surg 1964;46-A:267-82.

Requests for reprints to: Dr J McClure, Institute of Medical and Veterinary Science, Box 14, Rundle Street PO, Adelaide, South Australia 5000. 